\title{
Measurements of nozzle valve flow characteristics in a handy shower set
}

\author{
WOJCIECH WOLAK, KRZYSZTOF DUBAJ, ARTUR BARTOSIK \\ Department of Production Engineering \\ Kielce University of Technology \\ Al. Tysiaclecia P.P. 7, 25-314 Kielce \\ POLAND
}

\begin{abstract}
The paper deals with nozzle valve characteristics used in modern portable device, named handy shower, dedicated for personal hygiene. Such device significantly reduces water consumption and can be easily and quickly changed into a shower, sink or bidet. Importance of such device continuously rises as some regions and cities face water shortages. The aim of the paper is to measure and analyse characteristics of nozzle valves in portable handy shower for different hight of hydrostatic pressure, different number of holes in the nozzle and different level of valve opening. Experiments required measurements of volumetric flow rate and pressure drops. The pressure drops on the nozzle valve were measured using differential pressure transducer with accuracy of $1 \mathrm{~Pa}$, while the water flow rate at the outlet of the nozzle was measured using the time-volume method with accuracy for volume and time $1 \mathrm{ml}$ and $0.1 \mathrm{~s}$, respectively. Experiments confirmed substantial influence of hight of hydrostatic pressure, number of holes in the nozzle, and the level of valve opening on outlet water flow rate from the device. It is demonstrated that for chosen height of hydrostatic pressure and for filled water tank it is possible to calculate duration of the use of handy shower for specific hygiene purpose by choosing appropriate level of valve opening and the right nozzle valve with a certain number of holes. Authors discussed possible reason that some of measured points are scattered at low level of valve opening. Results of experience were presented as graphs and conclusions.
\end{abstract}

Key-Words: - Nozzle valve characteristics, Frictional losses, Decreasing water consumption

Received: June 10, 2020. Revised: December 28, 2020. Accepted: December 29, 2020. Published: January 4, 2021.

\section{Introduction}

Researches indicate that $97 \%$ of the water on the Earth is salt water and only $3 \%$ is freshwater, which is found mainly as groundwater. Humanity is facing a water crisis, due to industrial development, droughts, lack of rainfall, pollution or climate changes. Water crisis is manifested by economic competition for water quantity and quality, irreversible depletion of groundwater, and negative impacts on the environment. About 4 billion people live under conditions of severe water scarcity at least 1 month of the year. Additionally, half a billion people in the world face severe water scarcity all year round and half of the world's largest cities experience water shortages [1].

For above reasons, it is extremely important to respect water by implementing modern devices for personal hygiene that reduce water consumption, such as portable handy shower. Unfortunately, the popularity of such type of devices is still not fully satisfied. However, in countries facing water shortages there are increasingly used.

The handy shower is a portable device which contains water tank, valve and nozzle. It can be easily and quickly changed into a shower, sink or bidet. The valve and nozzle are built as one piece; therefore, it is named as nozzle valve. The nozzle valve is major component of handy shower and possess several holes around circuit of nozzle. Therefore, the number of wholes on the nozzle and level of valve opening are crucial factors affecting flow rate in the handy shower. Such relation, i.e., relationship between valve opening and flow rate is called the valve characteristics.

Based on the analysis of the literature, it can be concluded that the results of researches on the valves characteristics are available, however, they concern industrial valves applications [2], [3], [4], [5], [6], [7]. Among them there are some experiments on valve characteristics dedicated to successful operation of process plant and systems 
involves the highest level of control performance [8], [9], [10], [11], [12].

If valves for personal hygiene are considered, like this which exists in handy shower, it should be noted that manufacturers do not supply valve characteristics. Even in scientific literature there is lack of experiments that would provide valve characteristics used in portable devices for personal hygiene. Therefore, the paper is focused on measurements of nozzle valve characteristics in portable device, named handy shower.

A fluid flow through a pipe or valves causes energy loss due to shear stress counteracting movement. In order to determine energy losses, the hydraulic resistance should be defined, i.e., the resistance caused by the wall of a pipe in which the liquid flows [13], [14], [15]. The pressure drops between the inlet and outlet of a pipe or any obstacle, determining the pressure loss and depends on flow velocity, density and viscosity of flowing fluid, the length of a pipe, arcs or narrowing, pipe diameter and the level difference between inlet and outlet [16], [17]. Pressure drops can be measured or calculated using the Darcy-Weisbach algebraic equation or by solving the Navier-Stokes equations [18], [19].

The subject of the experiments presented in the paper is focused on nozzle valve characteristics, which deals with frictional losses, or more precisely with local pressure losses, occurring in the nozzle valve of handy shower set. The losses depend on the physical properties of flowing liquid, the level of valve opening, the number of holes in the nozzle and the flow rate, which depends on the height of the hydrostatic pressure and the diameter and length of the flexible hose. The flexible hose connects water tank with the nozzle valve.

The objective of paper is to determine the flow characteristics of the nozzle valves in the handy shower set for different heights of hydrostatic pressure, and for a different number of holes in the nozzle, and for different level of valve opening. Such experiments, which are presented as graphs are very useful for conscious users of handy shower set.

\section{Description of the portable handy shower}

Handy shower is a lightweight, portable and easy to use personal shower. The set allows to reduce water consumption in everyday hygiene activities. The outflow can be personalized for specific needs using interchangeable nozzle valve, which allows to choose both the right amount of water and the right size of the water stream. Weight of the full set is less than $0.4 \mathrm{~kg}$, making it convenient to transport, set up, store pack and unpack. The set consists of a flexible water tank of capacity 2 litters with a large handy water filler on the top with a tight lid. At the bottom of the tank there is a fitting to attach a flexible hose. The water tank is equipped with mounting holes, located in the upper part, intended for mounting to any object or surface. The user has the ability to regulate the water flow by adjusting the level of valve opening, as well as switching between the nozzles themselves appropriate to the needs of personal hygiene at a time.

The handy shower has possibility of manually controlling the device by holding the nozzle valve in a hand and thanks to the special grips included in the set, it is possible to attach the valve with a nozzle to any object and by means of a cord controlling water stream with any part of the body or permanently set the desired amount of outflowing water. As an alternative to controlling the valve by a hand, a lever included in the set gives an option to do it using a foot. Combined with the mentioned cord, the lightweight lever takes a form of pedal, suitable for placing it on the ground. After setting up the shower that way, contactless hygiene is possible. This affects high hygiene, because it reduces the risk of contact with viruses and bacteria, in case if several people use the device, which is especially important in days of Covid-19 spreading. Easily replaceable nozzle valve and a variety of nozzle valves contribute to the comfort of use. It is possible to quickly change the handy shower into a sink, shower or bidet.

The handy shower was mainly developed to people with limited access to water. This mainly applies to residents of developing countries, but also tourists, people working in the field or victims of disasters.

\section{Description of the test rig}

Experiments of flow characteristics of the nozzle valves in the handy shower were carried out at the Rheoflow Lab at the Department of Production Engineering at the Kielce University of Technology. General view of the test rig is presented in Fig. 1. The water tank of the handy shower (A) was mounted on a stand (B), performed for this purpose. The water tank was placed above the sink (C) and was connected with a flexible hose ended with a nozzle valve (C and D). The stand (B) was equipped by numerous hangers allowing adjustment of 
mounting height of water tank. In order to ensure constant hydrostatic pressure, the water was continuously supplied to the tank through inflow hose $(\mathrm{F})$ which is presented as scheme in Fig. 2. Excess of the water supplied to the tank by hose (F) was drained to the sink. The valve $(\mathrm{C})$ was equipped with pressure measuring hole located at inlet to the valve.

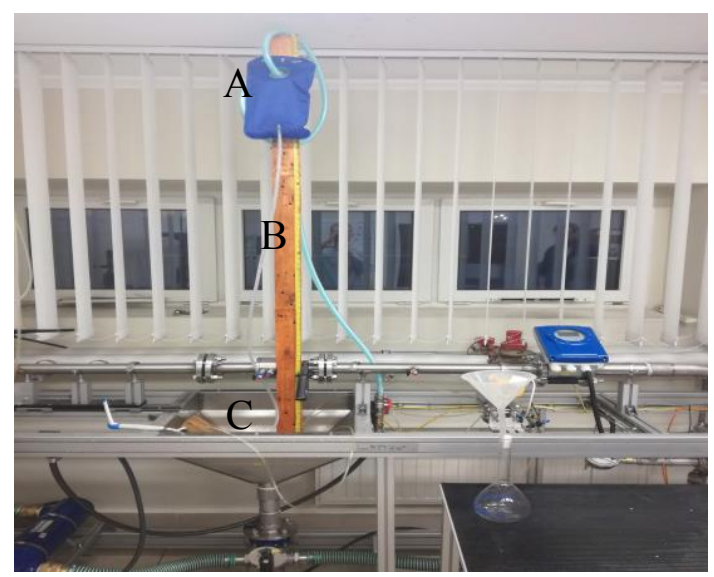

Figure 1. General view of the test rig. A - water tank; $\mathrm{B}$ - stand; $\mathrm{C}-$ sink. Own source

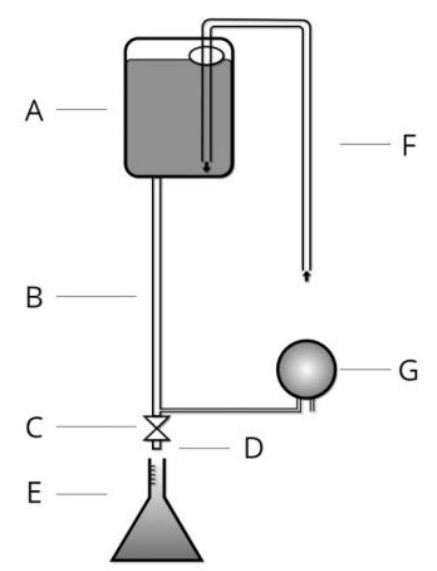

Figure 2. Scheme of the test rig.

A - water tank; B - outflow hose; C - valve; D - nozzle; $\mathrm{E}$ - glass container; $\mathrm{F}$ - inflow hose; $\mathrm{G}$ - differential pressure transducer. Source: Authors own elaboration

In order to measure pressure drops on the nozzle valve the differential pressure transducer has been used. The differential pressure transducer measured pressure difference between inlet to the valve and the outlet from the nozzle (D). Of course, the pressure at the outlet of the nozzle was the atmospheric pressure. The pressure drops on the nozzle valve were measured using a differential pressure transducer with an accuracy of $1 \mathrm{~Pa}$. The valve has the ability to adjust the opening level in the range from 0 to $12 \mathrm{~mm}$. Several types of nozzle valves have been used. Each of the nozzle valve had different number of holes distributed around circuit of nozzle.

In order to measure the flow rate at the outlet from the nozzle (D) the time-volume method was used. The nozzle (D) was placed right above a glass container (E). By measuring the volume of water flowing into the glass container (E) over time, it was possible to determine the rate of water outflow. The volume of water was measured with an accuracy of $1 \mathrm{ml}$, while the time with an accuracy of $0.1 \mathrm{~s}$.

The experiments consisted in specifying the height of the hydrostatic pressure, denoted as $\mathrm{H}$, and then measuring the pressure drops on the nozzle valve and determining the water flow rate for given nozzle valve. The height of hydrostatic pressure $(\mathrm{H})$ was determined in $[\mathrm{cm}]$ as the vertical difference between the water surface in the water tank and the level of symmetry axis of outflow from the nozzle. Based on the measurements made, the flow characteristics for each of the nozzle valves were obtained. The level of valve opening (n) ranged from 0 to $12 \mathrm{~mm}$. If $\mathrm{n}=0 \mathrm{~mm}$ the valve is fully closed. If $n=12 \mathrm{~mm}$ the valve is fully opened.

Individual nozzle valve can be recognized not only by the number of holes, but also by a hole size. For example, the diameter of a hole in the nozzle with one hole was equal to $3 \mathrm{~mm}$, while nozzle with 6 holes have a diameter of $1.5 \mathrm{~mm}$ each. However, each nozzle has identical diameters no matter how many holes it has.

The following nozzle valves included in the considered handy shower set were selected to experiments:

- nozzle with one hole with diameter of $3.0 \mathrm{~mm}$;

- nozzle with six holes with diameter of $1.5 \mathrm{~mm}$ each;

- nozzle with twelve holes with diameter of 1.7 mm each;

Taking into account time-volume method used for measurements of water flow rate it was necessary to estimate error of measurements. Considering volumetric flow rate, expressed as

$$
Q=\frac{V}{t}
$$

it was possible to obtain absolute error of measured volumetric flow rate, as follows:

where:

$$
\Delta Q=\left|\frac{1}{t}\right| \Delta V+\left|-\frac{V}{t^{2}}\right| \Delta t
$$

Q - volumetric flow rate, $\mathrm{m}^{3} / \mathrm{s}$

$t$ - outflow time of the measured water volume, $s$

$\mathrm{V}$ - measured volume of water, $\mathrm{m}^{3}$

$\Delta \mathrm{Q}$ - absolute error of volumetric flow rate, $\mathrm{m}^{3} / \mathrm{s}$ 
$\Delta t-$ absolute error of water outflow time, $s$ $\Delta \mathrm{V}$ - absolute error of water volume, $\mathrm{m}^{3}$

Assuming the least favourable character arrangement in equation (2), one can write absolute error of measured volumetric flow rate, as follows:

$$
\Delta Q=\frac{V \Delta t+\Delta V t}{t^{2}}
$$

The absolute error, expressed by equation (3), does not allow the accuracy of the measurement to be assessed. Therefore, instead of absolute error the relative error was applied, which can be written as follows:

$$
\frac{\Delta Q}{Q}=\frac{(V \Delta t+\Delta V t) t}{t^{2} V}=\frac{\Delta t}{t}+\frac{\Delta V}{V}
$$

Percentage relative error of measured volumetric flow rates were calculated for each of selected nozzle valves depending on the nozzle valve opening (n) and height of hydrostatic pressure (H). These values were shown in Table 1. It is seen from Table 1 that highest relative errors of volumetric flow rates exist for lowest height of hydrostatic pressure equals to $\mathrm{H}=50 \mathrm{~cm}$. The highest relative error was $1 \%$ for the nozzle with 1 hole and for the opening level $\mathrm{n}=1$.

Table 1. Percentage relative error of volumetric flow rate, denoted as $(\Delta \mathrm{Q} / \mathrm{Q}) 100 \%$, depending on the height of hydrostatic pressure $(\mathrm{H}=50,100,175 \mathrm{~cm})$ and the level of opening of the nozzle valve $(\mathrm{n}=1,5,12 \mathrm{~mm})$ and number of nozzle holes $(1,6,12$ holes $)$

\begin{tabular}{|c|c|r|r|r|}
\hline \multirow{2}{*}{$\mathbf{H}[\mathbf{c m}]$} & $\mathbf{n}[\mathbf{m m}]$ & $\mathbf{1}$ & \multicolumn{1}{|c|}{$\mathbf{5}$} & \multicolumn{1}{|c|}{$\mathbf{1 2}$} \\
\cline { 2 - 5 } & nozzle & $\mathbf{Q} / \mathbf{Q} \mathbf{1 0 0} \%$ & $\mathbf{Q} / \mathbf{Q} \mathbf{1 0 0} \%$ & $\mathbf{Q} / \mathbf{Q} \mathbf{1 0 0} \%$ \\
\hline \multirow{4}{*}{$\mathbf{1 7 5}$} & 1 hole & $0.87 \%$ & $0.24 \%$ & $0.24 \%$ \\
\cline { 2 - 5 } & 6 holes & $0.38 \%$ & $0.23 \%$ & $0.23 \%$ \\
\cline { 2 - 5 } & 12 holes & $0.35 \%$ & $0.22 \%$ & $0.20 \%$ \\
\hline \multirow{4}{*}{$\mathbf{1 0 0}$} & 1 hole & $0.99 \%$ & $0.27 \%$ & $0.26 \%$ \\
\cline { 2 - 5 } & 6 holes & $0.41 \%$ & $0.24 \%$ & $0.24 \%$ \\
\cline { 2 - 5 } & 12 holes & $0.35 \%$ & $0.22 \%$ & $0.21 \%$ \\
\hline \multirow{3}{*}{50} & 1 hole & $0.99 \%$ & $0.29 \%$ & $0.29 \%$ \\
\cline { 2 - 5 } & 6 holes & $0.53 \%$ & $0.27 \%$ & $0.26 \%$ \\
\cline { 2 - 5 } & 12 holes & $0.41 \%$ & $0.24 \%$ & $0.24 \%$ \\
\hline
\end{tabular}

\section{Results of measurements}

The measurements were made for three different heights of hydrostatic pressure, respectively: $\mathrm{H}=50 \mathrm{~cm}, 100 \mathrm{~cm}$ and $175 \mathrm{~cm}$ and for each of three selected nozzles, which contain 1, 6 and 12 holes, and for nozzle valve opening, respectively: $\mathrm{n}=1,2$, $3,4,5,12 \mathrm{~mm}$. Influence of the nozzle valve opening (n) on the water volumetric flow rate of the handy shower set for constant height of hydrostatic pressure equals to $\mathrm{H}=50 \mathrm{~cm}$ and for nozzles with 1 , 6 and 12 holes is shown in Fig. 3. Points marked on the Fig. 3 are obtained from measurements, while solid lines demonstrate interpolation of experimental data.

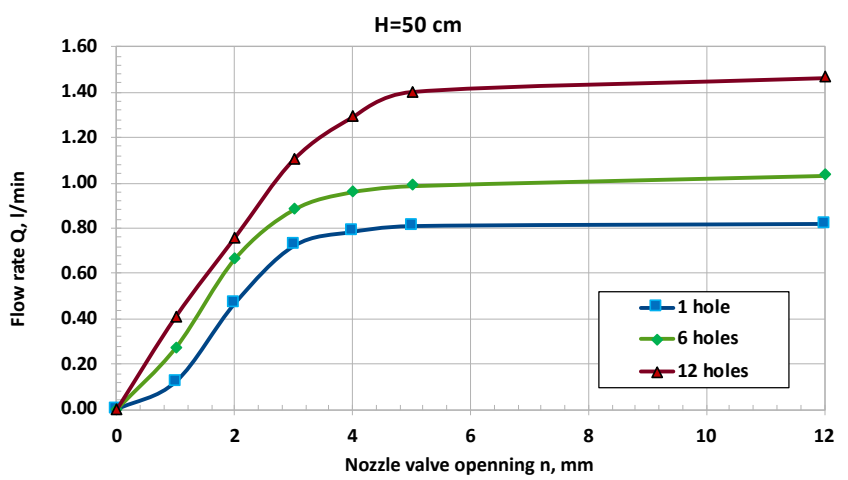

Figure 3. Nozzle valve characteristics depending on the nozzle valve opening for nozzles with 1, 6 and 12 holes and for $\mathrm{H}=50 \mathrm{~cm}$. Source: Authors own elaboration

In accordance with Fig. 3, as the nozzle valve opening increases the water flow rate increases too. However, when a nozzle valve opening is equal or higher than $\mathrm{n}=5$ the flow rate is almost the same. It follows that the valve design provides almost $100 \%$ of opening for $n=5$. There is significant influence of number of holes on water flow rate.

If nozzle valve with 6 holes is considered there would be about $30 \%$ of water saving in the same period of time comparing to nozzle valve with 12 holes, which is seen in Fig. 3.

Influence of the nozzle valve opening (n) on the water volumetric flow rate outflowing from the handy shower set for a constant height of hydrostatic pressure equals to $\mathrm{H}=100 \mathrm{~cm}$ and for nozzles with 1, 6 and 12 holes, is presented in Fig. 4.

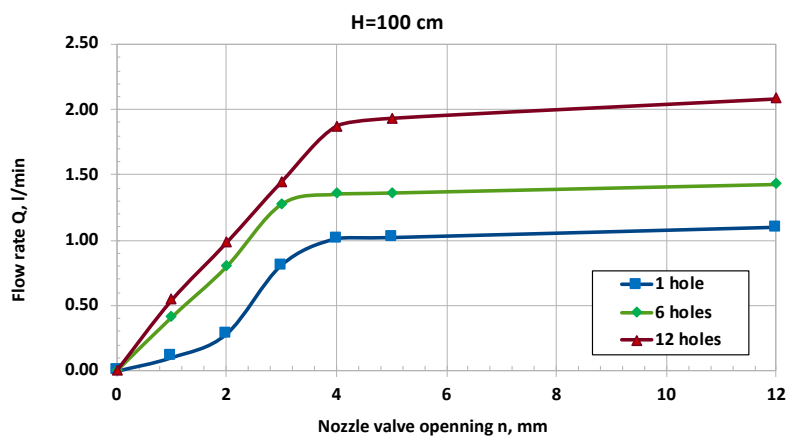

Figure 4. Nozzle valve characteristics depending on the nozzle valve opening for nozzles with 1,6 and 12 holes and for $\mathrm{H}=100 \mathrm{~cm}$. Source: Authors own elaboration 
The valve characteristics presented in Fig. 4 are qualitatively similar to the characteristics presented in Fig. 3. It follows again that as the valve opening level increases, the flow rate of water outflow from the nozzle valve increases too. If nozzle level opening is $n=5$ and number of nozzle holes is equals to 6 , the flow rate is about $35 \%$ higher comparing to flow rate for $\mathrm{H}=50 \mathrm{~cm}$. For valve opening level $\mathrm{n}>5$ only slight increase of the flow rate was observed. This means again that valve design provides almost $100 \%$ opening for $\mathrm{n}=5$.

The valve characteristics for $\mathrm{H}=175 \mathrm{~cm}$ is presented in Fig. 5. It is obvious that for constant nozzle valve opening the volumetric flow rate is higher comparing to $\mathrm{H}=50 \mathrm{~cm}$ and $\mathrm{H}=100 \mathrm{~cm}$, which was presented in Fig. 3 and Fig. 4, respectively. For instance, if nozzle valve with 6 holes is considered and level of valve opening is $\mathrm{n}=5$, the water flow rate is about $20 \%$ higher comparing to $\mathrm{H}=100 \mathrm{~cm}$ and about $65 \%$ higher comparing to $\mathrm{H}=50 \mathrm{~cm}$.

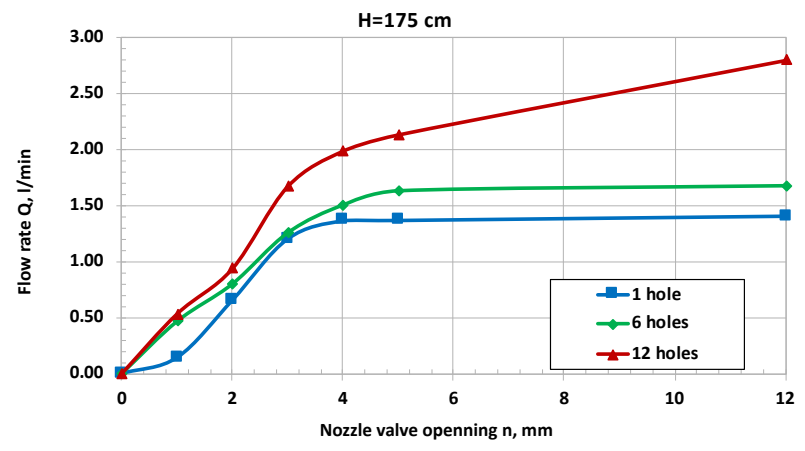

Figure 5. Nozzle valve characteristics depending on the nozzle valve opening for nozzles with 1, 6 and 12 holes and for $\mathrm{H}=175 \mathrm{~cm}$. Source: Author's own elaboration

Fig. 5 shows again that when the nozzle valve opening (n) is in the range from 0 to 5 , the flow rate significantly increases with the level of nozzle valve increase. Increasing the opening level for $n>5$ does not significantly affect the increase of flow rate. However, for nozzle with 12-holes, the impact of the valve opening level on the water flow rate seems to be significant.

Figures 3, 4 and 5 qualitatively look similar. However, it is surprising that experimental points do not lie on smooth curve if $\mathrm{n}<5$. In our opinion it is due to the fact that quality performance of nozzle holes is not perfect, which is particularly important for low Reynolds number, which is the case of this experiments.

Different approach of the nozzle valve characteristics is presented in Fig. 6. For the same hydrostatic pressure $\mathrm{H}$ there are collected experimental data of $\Delta \mathrm{p}=\mathrm{f}(\mathrm{Q})$ for each nozzle valve. For each value of $\mathrm{H}$, we used nozzles with three different numbers of holes, equal to 1, 6 and 12, and for each of them the nozzle valve opening (n) was changed from 0 to $12 \mathrm{~mm}$.

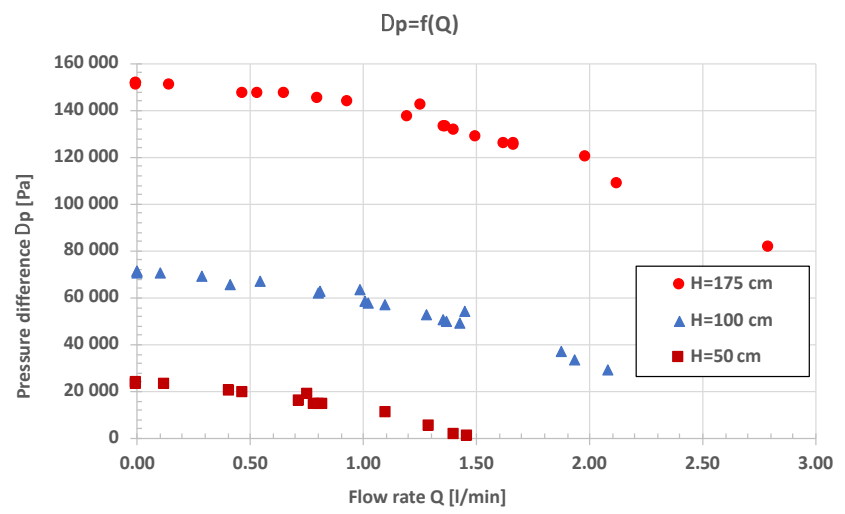

Figure 6. Nozzle valves characteristics for nozzles with 1, 6 and 12 holes. Source: Authors own elaboration.

Fig. 6 shows that for constant height of hydrostatic pressure, denoted as $\mathrm{H}$, the valve characteristics presented as $\Delta \mathrm{p}=\mathrm{f}(\mathrm{Q})$ are similar to the characteristics of a centrifugal pump. The nozzle valve opening and the number of holes in the nozzle are reflected in the output flow rate Q. The higher the level of nozzle valve opening or the larger the number of holes in the nozzle, the greater the output flow rate $\mathrm{Q}$ exists (for $\mathrm{H}=$ const.). The amount of hydrostatic pressure significantly affects the characteristics of the nozzle valve presented as relation $\Delta \mathrm{p}=\mathrm{f}(\mathrm{Q})$. Fig. 6 shows as well that the higher the value of the hight of hydrostatic pressure, the greater the flow rate Q. For example, for the height of hydrostatic pressure $\mathrm{H}=175 \mathrm{~cm}$, the possible range of handling the flow rate $\mathrm{Q}$ is from 0 to about $2.75 \mathrm{l} / \mathrm{min}$. On the other hand, for $\mathrm{H}=50$ $\mathrm{cm}$, the scope of operation with the expenditure Q varies only from 0 to about $1.5[1 / \mathrm{min}]$.

On the base of presented experimental data, it is interesting to see dependence of Reynolds number on frictional coefficient $(\zeta)$ for nozzle valves with different number of holes (n). Considering stationary flow and taking into account continuity equation in algebraic form, expressed as:

$$
A \cdot U=Q=\text { const }
$$

the cross-section averaged water outflow velocity in a hose (B) can be determined, as follows:

$$
U=\frac{4 \cdot Q}{\pi \cdot d^{2}}
$$

Finally, the Reynolds number can be described, as follows:

$$
R e=\frac{U \cdot d}{v}=\frac{4 Q}{\pi d v}
$$


where:

A - cross section of hose (B), $\mathrm{m}^{2}$

$\mathrm{d}$ - inner diameter of hose (B), $\mathrm{d}=0.005 \mathrm{~m}$

$\mathrm{Q}-$ volumetric flow rate of water in hose (B), $\mathrm{m}^{3} / \mathrm{s}$

Re - Reynolds number

$\mathrm{U}$ - averaged velocity across the hose (B), $\mathrm{m} / \mathrm{s}$

$v$ - kinematic viscosity of water at $20^{\circ} \mathrm{C}, \mathrm{m}^{2} / \mathrm{s}$

As all experiments were made for water temperature equals to $20^{\circ} \mathrm{C}+/-0.5^{\circ} \mathrm{C}$, therefore the water kinematic viscosity used for calculations was equal to $v=10^{-6} \mathrm{~m}^{2} / \mathrm{s}$.

Taking into account Darcy-Weisbach equation, dedicated for local losses, one can write

$$
\Delta p=\zeta \frac{\rho U^{2}}{2}
$$

Equation (8) allows to calculate frictional coefficient, as

$$
\zeta=\frac{2 \Delta p}{\rho U^{2}}
$$

where:

$\Delta \mathrm{p}$ - pressure drop on the nozzle valve, $\mathrm{Pa}$

$\zeta$ - frictional coefficient of the nozzle valve

$\rho \quad$ - water density $\rho=998.2 \mathrm{~kg} / \mathrm{m}^{3}$

Fig. 7 presents dependence of Reynolds number $(\mathrm{Re})$ on frictional coefficient $(\zeta)$ for nozzle valve with 12 holes and for hight of hydrostatic pressure $\mathrm{H}=175 \mathrm{~cm}$. The characteristics was made for the range of nozzle valve opening from $n=1$ to $n=12$.

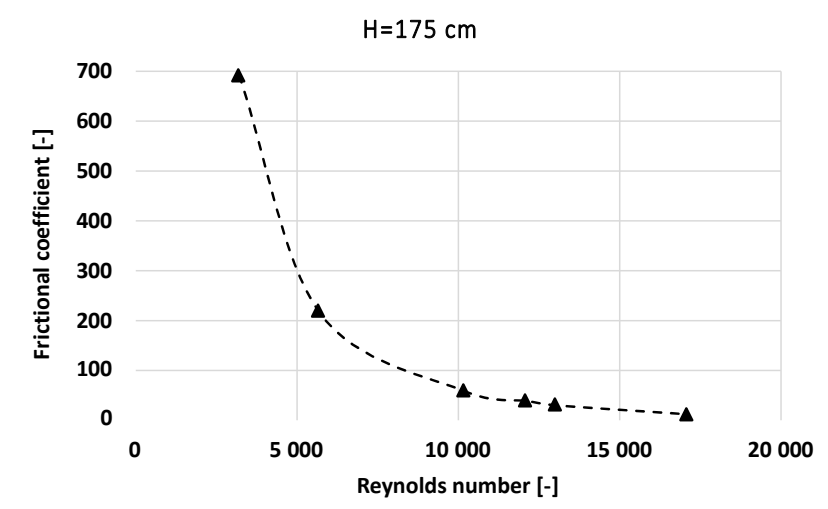

Figure 7. Frictional coefficient for nozzle valve with 12 holes in range of nozzle valve opening (n) from 1 to 12. Source: Authors own elaboration

It is seen in Fig. 7 that frictional coefficient is very high for low nozzle valve opening $(n=1)$ and in the contrast its value is low for high nozzle valve opening $(n=12)$. Qualitatively similar results can be obtained for nozzle valves with 1 and 6 holes and for other hight of hydrostatic pressure equal to 50 $\mathrm{cm}$ and $100 \mathrm{~cm}$.

\section{Conclusions}

Conscious user of the handy shower set should know the characteristics of the nozzle valve, particular the influence of the level of nozzle valve opening (n) and the hight of hydrostatic pressure (H) on the amount of water $\mathrm{Q}$ needed for a specific hygiene purpose.

For the purposes of this experiments three nozzles of the handy shower set were used, i.e., containing: 1,6 and 12 holes. Based on the presented graphs, it can be concluded that:

1. Number of holes in the nozzles and the level of nozzle valve opening significantly affect water consumption as it is seen on the nozzle valve characteristics presented by Fig. 3, Fig. 4 and Fig.5. If greater number of holes in the nozzle valve, the greater water consumption exists and showering time is decreasing.

2. Knowing the height of hydrostatic pressure $H$ and the water resources at our disposal, we can calculate the duration of the shower by choosing the right nozzle valve with a certain number of holes and the appropriate level of valve opening. For example, if we have a volume of 1 litter of water, and if the height of hydrostatic pressure is only $\mathrm{H}=50 \mathrm{~cm}$, and we would like to enjoy a shower for 1 minute at least, then we should choose a nozzle valve with 6 holes and set the level of valve opening to maximum $(n>5)$, as it is shown in Fig. 3.

3. When level of nozzle valve opening is in the range from $n=0$ to $n=5$, experimental points do not lie on a smooth curve. The possible reason could be related to quality of performance of nozzle holes. Quality of performance of nozzle holes is particularly important for low Reynolds number and can course substantial reduction of water flow rate.

Future research in this area will be focused on new generation of handy shower in which precision of nozzle holes will be improved. This probably will increase handy shower efficiency at low Reynolds number by decreasing frictional coefficient.

\section{References:}

[1] Ercin, A.E. and Hoekstra, A.Y., Water footprint scenarios for 2050: A global analysis, Environment Int., Vol. 64, 2014, pp. 71-82. 
[2] Bayomi, N.N., Abdel-Maksoud, R.M., Nawar, M.A. and Heikal, H.A., Valve with variable inherent characteristics, J. of Science and Technology, Vol. 9, No. 15, 2013, pp. 39-48.

[3] Jablonksa, J. and Kozubkova, M., Flow characteristics of control valve for different strokes, European Physical J., 2016, pp. 1-5.

[4] Kim, S.W., Kim, J.H., Choi, Y.D., Lee, Y.H., Flow characteristics of butterfly valve by PIV and CFD, New Trends in Fluid Mechanics Research, Proc. Fifth Int. Conf. on Fluid Mechanics, Tsinghua University Press and Springer, Shanghai, 2007, pp. 463-466.

[5] Xie, Y.D., Liu, Y.J., Wang, L.Y., Prediction model of control valve characteristics, Advanced Materials Research, Vol. 605-607, 2012, pp. 1345-1349.

[6] Li, W.H., Shao, W.L., Study of Flow Characteristics and Control Circuit on HighSpeed Solenoid Valve, Advanced Materials Research, Vol. 619, 2012, pp. 107-110.

[7] Mu, Y., Liu, M., Ma, Z., Research on the measuring characteristics of a new design butterfly valve flowmeter, Flow Measurements and Instrumentation, Vol. 70, 2019, pp.10161051.

[8] Kozlov, L.G., Polishchuk, L.K., Piontkevych, O.V., Korinenko, M.P., Horbatiuk, R.M., Komada, P., Orazalieva, S., Ussatova, O., Experimental research characteristics of counterbalance valve for hydraulic drive control system of mobile machine, Electrotechnical Inspection, No. 4, 2019, pp. 104-109.

[9] Herakovic N., Duhovnik J., Si ic M., CFD simulation of flow force reduction in hydraulic valves, Tehnicki vjesnik/Technical Gazette, Vol. 22, No. 2, 2015, pp. 453-463.

[10] Ritelli G. F., Vacca A., Energetic and dynamic impact of counterbalance valves in fluid power machines, Energy Conversion and Management, Vol. 76, 2013, pp. 701-711.

[11] Nawar, M.A., New valve with variable inherent performance for different system characteristics, Ph.D, Mechanical Power Dept., Faculty of Eng., Mataria, Helwan University, 2010.

[12] Jazi, A.M. and Rahimzadeh, H., Waveform analysis of cavitation in a globe valve, Ultrasonics, Vol. 49, 2009, pp. 577-582.

[13] Morrison, F.A., An Introduction to Fluid Mechanics, Cambridge University Press, New York, 2013.
[14] Bird, R.B., Stewart, W.E., Lightfoot, E.N., Transport phenomena, New York: John Wiley \& Sons, 1960.

[15] Schlichting, H., Boundary layer theory, McGraw-Hill, New York, 1968.

[16] Bartosik, A., Wojtyniak, T., The measurements of frictional losses in a slotted sieve, $18^{\text {th }}$ Int. Conf. Transport and Sedimentation of Solid Particles, Prague, 2017, pp. 27-34.

[17] Bartosik, A., Wojtyniak, T., Prediction of frictional losses in slotted sieves, $19^{\text {th }}$ Int. Conf. on Transport and Sedimentation of Solid Particles, Cape Town, 2019, pp. 24-27.

[18] Cebeci, T. and Smith, A.M.O., Analysis of turbulent boundary layers, Academic Press, New York-London, 1974.

[19] Cengel, Y.A. and Cimbala, J.M., Fluid Mechanics, McGraw Hill, 2006.

\section{Contribution of individual authors to the creation of a scientific article (ghostwriting policy)}

Wojciech Wolak and Krzysztof Dubaj organized and performed the experiments.

Artur Bartosik implemented method of measurements, and made calculations, and analysis.

\section{Sources of funding for research presented in a scientific article or scientific article itself}

The experiments presented in the paper were charity made under agreement with Handy Shower LLC.

\section{Creative Commons Attribution License 4.0 (Attribution 4.0 International, CC BY 4.0)}

This article is published under the terms of the Creative Commons Attribution License 4.0

https://creativecommons.org/licenses/by/4.0/deed.en US 